This item was submitted to Loughborough's Research Repository by the author.

Items in Figshare are protected by copyright, with all rights reserved, unless otherwise indicated.

\title{
Mind the gap: exploring the links between the expectations of relationship marketing and the reality of electronic-CRM
}

PLEASE CITE THE PUBLISHED VERSION

http://dx.doi.org/10.3316/IJEBM0202019

PUBLISHER

(c) RMIT Publishing

VERSION

AM (Accepted Manuscript)

LICENCE

CC BY-NC-ND 4.0

\section{REPOSITORY RECORD}

Doherty, Neil, and Nigel Lockett. 2019. "Mind the Gap: Exploring the Links Between the Expectations of Relationship Marketing and the Reality of Electronic-crm". figshare. https://hdl.handle.net/2134/10124. 
This item was submitted to Loughborough's Institutional Repository (https://dspace.lboro.ac.uk/) by the author and is made available under the following Creative Commons Licence conditions.

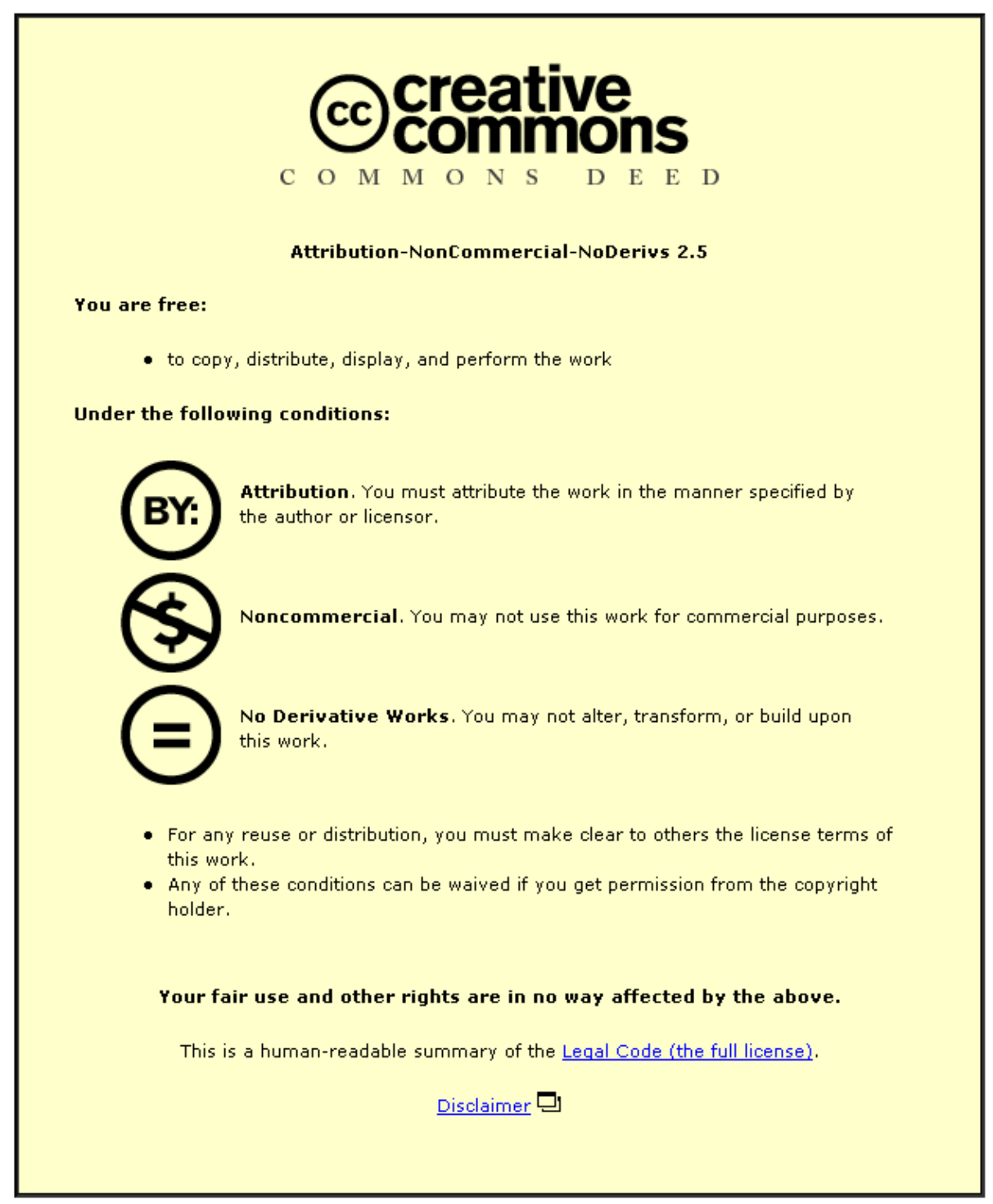

For the full text of this licence, please go to: http://creativecommons.org/licenses/by-nc-nd/2.5/ 


\title{
Mind the Gap
}

\section{Exploring the Links between the Expectations of Relationship Marketing and the Reality of Electronic-CRM}

\author{
Professor Neil F. Doherty \\ Loughborough University Business School, UK \\ Dr Nigel Lockett
}

Brunel Business School, Brunel University, UK

\begin{abstract}
The much debated relationship marketing paradigm suggests that the marketing strategy should be framed in terms of the development of long-term and mutually rewarding customer relationships, rather than simply focussing upon the promotion and selling of products and services. Moreover, customer relation management, typically enacted through electronic CRM software, is often promoted as the ideal mechanism for implementing relationship marketing on a company-wide basis. However, the question of whether the anticipated benefits of relationship marketing can actually be delivered through the application of e-CRM software is still one that needs to be addressed, empirically. To this end, this study develops a conceptual framework, which models the links between relationship marketing and e-CRM, before using this to explore the outcomes of the adoption of e-CRM applications by a sample of small to medium-sized enterprises (SMEs), operating in the mail order sector. The key findings presented in this paper are twofold: the driver for eCRM adoption has primarily been the need to integrate the front and back offices when operating in an increasingly complex multi-channel environment and, consequently, e-CRM has not delivered relationship marketing.
\end{abstract}

Keywords: Relationship Marketing, Customer Relationship Management, e-CRM, SMEs.

Marketing is no longer simply about developing, selling and delivering products. It is progressively more concerned with the development and maintenance of mutually satisfying long-term relationships with customers (Buttle, 1996). To this end, organisations are seeking to adopt 'relationship marketing' (RM) with the expectation that it will help them retain customers and in so doing deliver long-term and value-added customer relationships. The economic case for relationship marketing is clear: it is far cheaper to retain an existing customer than it is to win a new one, and RM has an important role to play in customer retention (Hunt \& Arnett, 2006). Moreover, the literature identifies a range of further benefits that should be realised from a relationship marketing strategy, including: longer-term relationships; more frequent customer contact; heightened focus upon customer service and 
the tailoring of products and services; and increased customer satisfaction (Payne, 2000b; Leverin \& Lilijander, 2006).

Given that the adoption of relationship marketing appears to offer organisations very real commercial benefits, it is not surprising that many are keen to embrace its principles, but this may be far easier said than done, as its desired output is far easier to specify than are its underlying processes and practices. However, many practitioners and academics argue that relationship marketing can be operationalised through the adoption of customer relationship management (Ryals \& Knox, 2001), as it has a clearer action-orientation than relationship marketing, as reflected in its definition: 'the strategic use of information, processes, technology and people to manage the customer's relationship with your company, across the whole customer life cycle' (Kincaid, 2003, p. 41). Despite the broad focus of this definition, in recent years, it is the technological perspective that has gained the ascendancy, and for most organisations, the adoption of CRM is achieved through the implementation of software, which typically comes with the label 'electronic customer relationship management' (e-CRM). Indeed, the annual global expenditure on CRM technology is already huge and growing year on year (Fjermestad \& Romano, 2003; Feinberg \& Kadam, 2002), driven at least in part by the expectation that it will provide a shortcut to the development of a relationship marketing capability (Light, 2003). However, what is not clear from the extant literature is whether a typical e-CRM implementation has sufficient richness, capacity and sophistication to deliver a relationship marketing strategy. To help fill this gap in the literature, this paper seeks to explore these issues by undertaking an empirical study investigating the use of e-CRM by small to medium-sized enterprises (SMEs) in the mail order sector and compares these with our conceptual model of relationship marketing. The paper is divided in to four remaining sections, namely: the conceptual framework, research approach, key findings and conclusions.

\section{Literature Review and Conceptual Framework}

The aim of this section is to provide an overview of the key concepts-relationship marketing $(\mathrm{RM})$, customer relationship management (CRM) and electronic customer relationship management (e-CRM) - before exploring the relationship between them and then using this to derive a conceptual framework and set of objectives for this study.

\section{Relationship Marketing [RM]}

Based upon an extensive review of the literature, Harker (1999, p. 16) proposed that an organisation could be said to be practising relationship management if it is: 'proactively creating, developing and maintaining committed, interactive and profitable exchanges with selected customers (partners) over time'. As it is far cheaper to retain an existing customer than it is to win a new one, the economic case for developing such long term relationships is clear (Payne, 2000a), and as Reichheld (2001) notes there is a very strong correlation between the loyalty of an organisation's customers and its profitability. However, whilst improved customer loyalty and retention may be the principle driver for initiating a 
relationship marketing strategy, it has been suggested that there are many other potential benefits (Gronroos, 1999; Morris et al., 1998; Payne, 2000b; Hunt \& Arnett, 2006), such as:

- Longer term customer relationships;

- Enhanced customer service perspective;

- Higher quality and more frequent customer contact;

- Personalised products and services;

- Enhanced delivery of customer value;

- Enterprise-wide participation in marketing;

- Enterprise-wide responsibility for quality.

Whilst the potential benefits of engaging in relationship marketing may be relatively easy to identify, many commentators are now questioning whether the models of relationship marketing that have been introduced, thus far, have delivered any significant improvements in either customer or company value (Ballantyne, 2004; Gummeson, 2004; O'Malley \& Prothero, 2004). On the other hand, many researchers, including some who expressed reservations about its current value, are optimistic that relationship marketing still has a bright future (Gummeson, 2004; Payne \& Frow, 2005). Indeed, a recent Delphi Study (Bonnemaizon et al., 2007), found that a sample of academics and practitioners were still very positive that relationship marketing has a very important role to play in the coming years. Amongst all this uncertainty, what has become clear is that to be effective, any relationship marketing strategy will require a significant investment in human resources and organisational change (Kotorov, 2002). More specifically, the following composite list of activities and best practices presents the more common prescriptions with respect to the effective conduct of relationship marketing (Buttle, 1996; Gronroos, 1999; Gummesson, 1996; Hunt \& Arnett, 2006):

- The development of a supportive culture;

- The initiation of internal marketing;

- A sophisticated customer-oriented database;

- The ability to understand customer expectations;

- The ability to re-design market offerings in support of customer expectations;

- Re-designed business processes to support relationships;

- An organisational reward scheme to support relational behaviours.

In summary, although the anticipated outcomes of relationship marketing appear to be extremely attractive, their realisation will require the enactment of a-potentially extensive and disruptive-programme of organisational investment and change (Peppard, 2000). Indeed, it could be that some of the recent questions asked with respect to the effectiveness of relationship marketing, may have arisen because organisations have been either unable or unwilling to make the required investment in radical organisational change. 


\section{Customer Relationship Management}

CRM has been defined as a business process that 'addresses all aspects of identifying customers, creating knowledge, building customer relationship and shaping their perceptions of the organisation and its products' (Srivastava et al., 1999, p. 169). As one might suspect from this definition, CRM is very firmly rooted in the principles and practices of relationship management (Zablah et al., 2004). Indeed, it has been argued (Ryals \& Knox, 2001; LeeKelley et al., 2003) that CRM provides organisations with the means to implement relationship marketing on a company-wide basis. Indeed, as the terms are now so closely related (Jain \& Singh, 2002), it is instructive to review the key characteristics of CRM (Ryals \& Knox, 2001), as presented below, which highlights just how similar it is to relationship marketing:

- Adoption of a strong and explicit customer orientation;

- Comprehensive collection and storage of integrated customer information;

- Use of dedicated data analysis software;

- Segmentation of customers by their anticipated life-time value;

- Re-engineering of business processes to deliver customer value;

- Profiling of customers to enable tailored delivery of products and services;

- A strong focus on managing customer, as opposed to product portfolios.

Whilst it can be seen that these characteristics show a high degree of similarity to the outcomes of relationship marketing, a careful comparison does identify a number of appreciable differences. For example, the characteristics of CRM tend to be rather more pragmatically defined in terms of means, rather than ends. Moreover, it is interesting to note that the more philosophical elements of relationship marketing-such as enterprise-wide marketing / quality assurance-do not appear on the list of CRM attributes. The final, and perhaps the most telling, distinction between relationship marketing and CRM is that there is a far more explicit emphasis on the role of technology and increasingly in the form of e-CRM, within any discussion of the characteristics of CRM.

\section{Electronic Customer Relationship Management}

There are a wide variety of views as to the underlying nature of CRM: is it a process, a strategy, a philosophy or a technology (Greenberg, 2001)? Indeed these multiple perspectives are often reflected within its definition: 'a comprehensive business and marketing strategy that integrates technology, process and all business activities around the customer' (Anton \& Hoeck, 2002). However, in recent years, it is the technological perspective that has gained the ascendancy, as it is typically through the purchase of e-CRM software that organisations become engaged in customer relationship management (Massey et al., 2001). The term e-CRM is typically used to describe a broad range of technologies that might helpfully support and facilitate a company's CRM strategy, including 'web-sites, email, data capture, data warehousing and data mining' (Lee-Kelley et al., 2003, p. 241), but it is increasingly the Internet that plays the most significant role. Consequently, as Dussart 
(2001, p. 633) notes, the adoption of a web-enabled e-CRM package is viewed as 'the ideal platform for practising relationship marketing'.

\section{The Relationship between RM and e-CRM: Exploring the Gap}

Based upon the above analysis, highlighting the very close interdependencies between relationship marketing, CRM and e-CRM, it is possible to argue that an obvious strategy, for any company wishing to benefit from the adoption relationship marketing, is to implement an e-CRM application. Consequently, it is interesting to pose the question: to what extent does e-CRM technology deliver the expected returns of relationship marketing? The problem seems to be that whilst the relationship marketing literature promises a vast array of significant benefits, thus far there is little evidence that e-CRM technology is able to deliver on these promises. For example, Feinberg and Kadam (2002, p. 432) contend that there is no proven link between the implementation of e-CRM technology and the delivery of significant improvements in terms of 'customer satisfaction, sales, profits, or loyalty'. Indeed, there is a growing body of literature that raises serious questions about the success of CRM, in general, and e-CRM technology, in particular (Adebanjo, 2003; Rheault \& Sheridan, 2002; Rigby et al., 2002; Yu, 2001; Fjermestad \& Romano, 2003). One highly plausible reason for the dissatisfaction with e-CRM technology is that they are not fulfilling the promise of relationship marketing. As Trembly (2002) reported, there is the unrealistic expectation, within many organisations, that the implementation of CRM technology will deliver the full suite of benefits associated with RM. This potentially significant expectations gap has been depicted in Figure 1.

\section{Insert figure 1 about here}

\section{Conceptual Framework and Research Objectives}

Having identified a potentially critical expectations gap, it is important to investigate why it might have arisen. Based upon a critical review of the literature (Gronroos, 1999; Gummesson, 1996; Hunt \& Arnett, 2006), we would argue that for any organisation to stand a realistic chance of attaining its benefits, the organisation would need to adopt a holistic view of relationship management, as reflected in Figure 2. Adopting such a view means recognising that whilst e-CRM technology may well be a necessary condition for effectively tackling the challenges of relationship marketing, it is very unlikely to be sufficient on its own. More specifically, e-CRM technology can be an important conduit that facilitates the capture of high quality 'preference-related' data from the customer, whilst simultaneously directing tailored, marketing-oriented information to the customer. However, too often in practice, eCRM implementations offer a relatively narrow range of primarily sales-oriented features (Feinberg \& Kadam, 2002). Moreover, for the software to be successful, this critical interface has to be supported by a raft of customer-focused organisational changes to ensure that the promises of customer value, such as offered by e-commerce, are delivered in practice (Peppard, 2000). Moreover, it is important to recognise that e-CRM may not be the only channel through which an organisation will attempt to facilitate relationship marketing. For example, e-commerce sales may be supported by a range of complementary channels, such as call centres, offline marketing, postal and potentially mobile computing interfaces. In the multi-channel environment, the role of the database also becomes increasingly important, to 
ensure that all the customer-related data is effectively integrated, analysed and translated into consistent customer-focused information.

\section{Insert figure 2 about here}

Whilst the literature has been highly influential in the derivation of our holistic view of relationship marketing, the extent to which organisations have been successful in translating the promise of e-CRM into practice, by adopting such an holistic approach, has not been empirically evaluated. Consequently, we wanted to undertake an empirical study to address the following two objectives:

Objective 1: To explore the extent to which the actual drivers for the adoption of e-CRM projects align with the anticipated deliverables from relationship marketing initiatives. More specifically, we sought to explore whether e-CRM software had been purchased with the express purpose of delivering enhanced customer relationships, improved customer retention, higher quality customer contacts and so forth.

Objective 2: To explore the extent to which the actual constituent elements of targeted eCRM initiatives align with the anticipated components of Relationship Marketing Initiatives. More specifically, we sought to explore the extent to which organisations had modified their culture and practices, and introduced reward schemes and internal marketing in support of their new technology.

The following section is used to present the research method that was designed to address these two objectives.

\section{Research Approach}

In terms of our philosophical perspective, this empirical study can be broadly categorised as 'interpretive' as our aim was to gain 'knowledge of reality through the study of social constructions, in particular, language and documents' (Klein \& Myers, 1999). As Walsham (1993, pp. 4-5) notes, interpretive approaches are particularly helpful in 'producing an understanding of the context of the information system (e.g. an e-CRM application), and the process whereby the information system influences and is influenced by the context'. The aim of this section is to present our targeting strategy, and data collection and analysis approaches, which ultimately enabled effective interpretations from our chosen research domain to be derived.

\section{Research Targeting}

Having established the research objectives, it was possible to define the targeting strategy, namely a sample of small to medium-sized enterprises (SMEs), operating in the mail order sector, that had recently adopted e-CRM. The decision to target mail order companies could be justified on two counts. Firstly, as mail order companies tend to be rather isolated from their customers, CRM may be an effective way of bringing them closer together, virtually, if not physically. Secondly, mail order companies have been enthusiastic adopters of the 
Internet (Doherty et al., 1999), and are therefore very likely to be engaged in multi-channel retailing. There are also a number of reasons why it made sense to explicitly focus upon SMEs. Firstly, there is a significant gap in the literature in this area: there is a fairly limited body of research on the uptake of e-CRM within SMEs (e.g. O'Toole, 2003), but little or no discussion of its impact, nor its association with relationship marketing. Secondly, SMEs have one significant advantage, and one significant disadvantage, as compared with their larger counterparts when it comes to using e-CRM to leverage the benefits of relationship marketing. Their advantage is that because they are small, flexible and typically have fairly simple structures and processes, the re-engineering of processes and the internal marketing effort might be somewhat easier. However, as SMEs are also typically limited in terms of their financial and personnel resources, they might be simply tempted to implement the software without making the necessary organisational changes. Consequently, it was envisaged that by targeting SMEs within the mail order sector, we would be able to explore which of the two potential outcomes is the more prevalent. The decision to target companies that had all recently implemented the same proprietary brand of e-CRM software was based upon the desire to reduce the number of competing variables: any observed variance in the research variables could not be attributed to variability in the systems adopted.

\section{Data Collection Approach}

To gain the necessary in-depth interpretations surrounding the implementation and impact of e-CRM applications within SMEs, a multiple case study approach was adopted. This has been defined as 'an empirical enquiry that investigates a contemporary phenomenon within its real life context', which 'relies on multiple sources of evidence' (Yin, 1994, p. 13). To compile an appropriate sample of SMEs operating in the mail order sector, an independent software vendor (ISV) which specialised in providing e-CRM applications was approached for their assistance in gaining access to their client firms. An invitation was granted to the ISV's annual customer forum in order to present the aims and objectives of the study to their customers. Of the 16 customers present, nine agreed to cooperate by allowing access to senior managers in the companies.

In terms of the specific data collection method to adopt, Walsham (1995, p. 78) suggests that in the context of interpretive studies, interviews are arguably the primary data source, as they provide the 'best interpretations that participants have regarding the actions and events that have, or are taking place'. Consequently, the interviewing of a variety of key stakeholders was chosen as our primary data collection method. More specifically, the data was collected through the use of semi-structured interviews with senior managers in small mail order companies, each of which had recently implemented the same brand of e-CRM software. A total of 16 telephone interviews from these nine case organisations were conducted. Each interview was conducted using a pre-declared interview structure (Appendix I), derived from relevant theory in the marketing and information systems' domains, and was designed to support rich and comprehensive responses. The same researcher conducted all the interviews in order to provide some level of internal consistency. All interviews were digitally recorded and transcribed, by the same typist for all interviews, and resulted in 9 hours and 41 minutes of audio files and 82,614 words of 
transcription. To improve the clarity and richness of the interview responses, in some cases a series of follow-up questions were posed via email. Finally, Klein and Myers (1999) argue that it is important when conducting interpretive research to set the subject matter in its social and historical context. To this end profiles of each of our nine case study organisations have been presented in Table 1.

Insert table 1 about here

\section{Data analysis strategy}

The QSR NUD*IST Vivo [NVivo] software was chosen as the primary tool for the management and analysis of the qualitative data, as it provides a range of tools for handling rich data records, for browsing and enriching text, coding it visually, and for grouping the data records by many categories. The source data to be analysed, for each case study, comprised the verbatim transcripts from interviews. All this data was entered into the (NVivo) software, which was then used to code of all the source documents and the retrieve data from them. Codes were created and applied for all the key variables associated with our two stated research objectives. For example, codes were used to highlight and then collate signs of customer retention, relationship development, customer loyalty, organisational change and personalised marketing. Whilst NVivo was used as the main data analysis tool, an innovative feature of the research design was the use of two alternative approaches to qualitative data analysis to validate and triangulate the findings, namely: audio file codification and computer-mediated corpus analysis. A brief summary of all three analysis approaches is presented in Table 2

Insert table 2 about here

The multiple-approach analysis strategy was ultimately judged to have been a great success, as not only did it provide a very rich and sophisticated picture of the research domain, it also helped to provide added confidence in the research findings, as presented in the following section.

\section{Research Findings}

Based upon the analysis of the research data, as described above, it was possible to deliver some important new insights with respect to our stated research objectives, as presented in the following two sections.

\section{The Drivers for e-CRM Initiatives}

The following five key findings with respect to the drivers for e-CRM initiatives all provide evidence that the motivations for the adoption of e-CRM were not based upon any conscious desire from our case companies to engage in relationship marketing.

The Internet changes the strategic environment: Previous research suggests that the Internet offers businesses a wide range of opportunities and potential benefits (Doherty et 
al., 2003), which SMEs, in particular, have proved keen to exploit (Daniel \& Grimshaw, 2002). It was not then particularly surprising to find that in nearly all our cases, the Internet was viewed as an increasingly important new channel, representing (on average) over 25 per cent of sales per annum (see Table 1: columns 6-10). Indeed, for some organisations, it was already the most important channel in terms of sales turnover. One company representative stated: 'the web will be our main channel in 12 months, our target is 65 per cent but we will not withdraw from other channels'. Not only was the Internet viewed as an important new channel to market, it was also seen as a driver of innovation. One respondent commented that the Internet is: 'giving consistent growth' and 'the way forward is being driven more and more to the Internet. We want to start using SMS marketing and have interactive monitoring by call centre staff so we can interact with customers whilst they are online'. The short-term objective of another smaller company was articulated as: 'next year we want to sell in different currencies over the web; we want online order tracking with links to carriers; we will be relying more and more on the web site and targeting through web customer more effectively'. From a relationship marketing perspective, this is a potentially important development, as the web facilitates the automatic capture of a wealth of customerrelated data, which could be used to build a richer picture of customers, to allow communications and offers to be appropriately tailored. However, there was no indication from our participating companies that this potential had in anyway influenced their e-CRM adoption decision.

E-CRM is required to manage a multi-channel environment: The rapid uptake of online selling had thrust all the organisations into a multi-channel environment. As noted earlier, the vast majority were actively engaged in Internet-based selling, in support of their traditional mail order operations, which in turn were often supported by call centres and less frequently shops. Typical statements from respondents included: 'we are a multi-channel multi-brand business with telephone calls automatically routed by telephone agents' skills'; 'we are a multi-channel business - telephone orders are remaining the same in monetary terms but they are decreasing in proportion to Web sales'. Whilst the move towards a multi-channel environment was generally viewed positively-channels are perceived to be mutuallysupportive and complementary - it posed many challenges for the case organisations, particularly in terms of communication and co-ordination. Respondents stated that: 'customers on the [web] site seem to be looking at the printed catalogue'; 'the first purchase is often retail and they then use other channels - including the Web'. In response to this challenge, the adoption of e-CRM was seen as an ideal mechanism for providing an efficient and consistent approach to order capture and processing, across all channels (Payne \& Frow, 2004).

E-CRM effectively manages high quality mailing information: The long-term success of mail order operators is predicated upon the availability of high quality mailing information, to facilitate targeted communication with existing and potential customers. Both the Internet and e-CRM were seen as important and complementary tools for both extending and improving the quality of the organisations' mailing information. More specifically, the Internet was considered to be an excellent source of new email addresses - both when customers signed up for information on 'new products and that sort of thing', and 'when they are buying 
something, we capture their address details'. Whilst it was recognised that e-CRM also provides the capability for effectively maintaining and exploiting those addresses, once captured, there was little evidence that this capability had been exploited.

E-CRM links the front and back offices: As mail order operators grow, primarily in terms of turnover, the challenge of effectively managing the sales process-from the receipt of an order, through order fulfilment, through to payment-becomes more complex. Consequently, many of the participating organisations had invested in e-CRM as a means of automating the sales order capture and fulfilment process, and in so doing, establishing a coherent link between their front and back offices. As one respondent noted: 'we use e-CRM for the whole of our sales order processing - from the moment the order comes into the building it goes straight into e-CRM, which then tracks the order, obtains payment, checks on stock, produces out of stock risk for ordering new stock, checks on the availability of stock in the warehouse and when the goods are in the warehouse will produce a picking list with the orders'. In a similar vein, another respondent noted that her company uses e-CRM 'to manage the sales process from beginning to end'. Once more, the rationale for implementing the e-CRM software was primarily based upon the technology's ability to automate and integrate standard business processes, rather than its potential to facilitate higher quality customer relationships.

E-CRM delivers customer-oriented information: Zuboff (1988) was one of the first academics to question whether information technology's primary role was to 'automate', or to 'informate'. Amongst the case companies, the informational powers of e-CRM were undoubtedly valued, particularly in terms of sales, click-stream, leads and returns analyses. For example, one company representative noted that they now paid far more attention to 'when and how orders were placed, and by whom'. However, such informational outcomes were generally presented in a highly aggregated form, in support of an efficient and effective sales process, and there was no evidence that information on the behaviour of individual customers was being produced to facilitate the personalisation of communications, products or offers. As one respondent noted, rather embarrassedly, when asked about the extent to which communications were tailored to facilitate customer retention: 'yes, well, we do mail our email database with a newsletter twice a month'.

\section{The Components / Outcomes of e-CRM Initiatives}

Having seen that the development of long lasting customer relationships to facilitate customer retention was not an explicit driver of our case companies' e-CRM initiatives, it did not come as any great surprise to discover that none of them had undertaken a programme of customer-oriented organisational change in support of their new software. More specifically, there was little evidence to suggest that the case organisations have redesigned any business processes, working practices or organisational structure, to facilitate the planned outcomes of relationship marketing initiatives. Indeed, e-CRM is generally being used to simply automate and integrate existing processes, rather than as a catalyst for process improvement. As one respondent noted, 'we have been automating more and more 
areas of our business, so essentially our vision, at the moment, is to continue doing that'. In a similar vein, other respondents commented that: 'more automation of picking and dispatch is needed', and their IS strategy is 'based upon standardisation and automation'. A similar pattern of simple automation was found with respect to generating customer communications. As one respondent noted, 'we are using IT to email our customers a lot more frequently', but, as he later acknowledged, such emails were in no way being tailored or personalised to meet the needs of individual customers.

Finally, in terms of the overall impact of e-CRM, it can be concluded that there is little evidence that organisations have been successful in achieving the planned outcomes of relationship marketing initiatives. A number of companies mentioned the potential of e-CRM to facilitate customer segmentation / profiling, and also to increase the value of individual orders. For example, one company representative commented that they were hoping to 'increase the order value' by 'offering people far more of a targeted proposition in terms of product'. However, another commented that whilst they had experimented with segmentation, it 'is done at quite broad levels simply because I don't believe we hold enough personal information on these individuals'. Another made the telling comment that they would like to develop meaningful customer relationships, but it wasn't possible to do it an 'individual level, simply because there are too many of them'. In a similar vein, another respondent stated that they were 'using purchasing profiles but we are only just beginning to take this seriously enough and are now outsourcing it to a specialist'; as the respondent went on to comment, 'we are losing money on every new customer, so segmentation is critical'. Consequently, whilst there was some acknowledgement of the technology's relationship building and customer retention potential, the consensus view was that very little, if any, meaningful attempts had been made to utilise them. As one respondent admitted, when questioned about his organisation's success at developing rewarding customer relationships: 'we could be much better on that I have to say'. The most likely explanation for this disappointing outcome, as noted earlier, is that our case companies primarily viewed e-CRM as a mechanism for automating the processing of sales, rather than facilitating the development of mutually beneficial relationships.

\section{Conclusions}

There may be very substantial bodies of literature with regard to relationship marketing, customer relationship management, and electronic customer relationship management, but to date there have been very few contributions that have explicitly and empirically sought to establish the nature of the relationship between these important and highly interdependent concepts. More specifically, there have been no empirical studies seeking to establish the extent to which e-CRM technology can help to realise the important potential of relationship marketing, particularly for SMEs. Consequently, we believe that our current study, described and contextualised in this paper, should ultimately make a very important contribution to the literature by exploring how e-CRM has been utilised by SMEs, and the extent to which its potential has been leveraged in order to develop more productive, long-term relationships with their customers. Unfortunately, our findings demonstrate that there is a very significant gap between the potential of relationship marketing and the reality of e-CRM: our case study 
companies are typically using e-CRM as a tool for more effectively managing the sales order process, rather than as a proactive approach to the development and maintenance of productive customer relationships. Whether the limited ambitions of the case organisations or limitations in the scope and functionality of the software might help to explain this gap in performance is still not totally clear, but the most likely explanation is that our sample of SMEs have simply not been prepared to make the required investments in organisational change and staff development necessary to leverage an e-CRM investment (Peppard, 2000; Kotorov, 2002).

These findings offer a number of important implications for managers, particularly those working in a multi-channel, SME context. The most important implication is that the introduction of e-CRM software can make a very important contribution to organisational effectiveness, even if its role is fairly narrowly defined. Moreover, it has been shown that eCRM has a particularly important role to play in a multi-channel environment. However, practitioners need to understand that e-CRM will not deliver a relationship marketing paradigm unless it is implemented as part of a wider initiative that is clearly defined, well resourced and above all used as a catalyst for wider organisational change. More specifically, organisations must be prepared to radically rethink their processes and modify their views of, and behaviour towards, their customers if a meaningful instantiation of relationship marketing is to be achieved. It is envisaged that our study should also be of interest to the researcher. Not only does it deliver some important new insights into the role and impact of e-CRM, it also demonstrates how the application of complementary analysis tools can provide added confidence in the resultant findings.

Research into the adoption of innovative technology, within the organisational context, is always a potentially problematic undertaking, and therefore contains a number of inherent limitations. In particular, the adoption of the case study format restricted the number of organisations that we could engage with, and it was also disappointing that we were not able to find any who had explicitly adopted a relationship marketing strategy, which could have been explored. Consequently, whilst this study provides many interesting and novel insights, these limitations highlight the need for follow-up studies to be conducted employing different methods, and targeting different populations and respondents. 


\section{References}

Adebanjo, D. (2003). Classifying and selecting e-CRM applications: An analysis-based proposal. Management Decision, 41(6), 570-577.

Aanton, J., \& Hoeck, M. (2002). e-Business customer service. Santa Monica, CA: The Anton Press.

Ballantyne, D. (2004). Pathways less travelled to value creation: Interaction, dialogue and value creation. Journal of Business \& Industrial Marketing, 19(2), 97-98.

Bonnemaizon, A., Cova, B., \& Louyot, M. C. (2007). Relationship marketing in 2015: A Delphi approach. European Management Journal, 25(1), 50-59.

Buttle, F. (1996). Relationship marketing theory and practice. London: Paul Chapman Publishing.

Daniel, E. M., \& Grimshaw, D. J. (2002). An exploratory comparison of electronic commerce adoption in large and small enterprises. Journal of Information Technology, 17(3), 133-147.

Doherty, N. F., Ellis-Chadwick, F. E., \& Hart, C. A. (1999). Cyber retailing in the UK: The potential of the Internet as a retail channel. International Journal of Retail and Distribution Management, 27(1), 22-36.

- (2003). An analysis of the factors affecting the adoption of the Internet in the UK retail sector. Journal of Business Research, 56(11), 887-897.

Dussart, C. (2001). The transformative power of e-Business over consumer brands. European Management Journal, 19(6), 629-637.

Feinberg, R., \& Kadam, R. (2002). E-CRM web service attributes as determinants of customer satisfaction with retail web-sites. International Journal of Service Industry Management, 13(5), 432-451.

Fjermestad, J. \& Romano, N.C. (2003) 'Electronic customer relationship management: revisiting the general principles of usability and resistance - an implementation framework', Business Process Management Journal, 9 (5), 572-591.

Greenberg, P. (2001). CRM at the speed of light. Berkley, CA: McGraw-Hill.

Gronroos, C. (1999). Relationship marketing: Challenges for the organisation. Journal of Business Research, 46, 327-335.

Gummesson, E. (1996), "Relationship marketing: the Emperor's new clothes or a paradigm shift?", in Schoneberg, U. (Ed) , Research Methodologies for The New Marketing, ESOMAR / EMAC Symposium, Vol. 204, Amsterdam, pp. 3-19.

Gummesson, E. (2004). Return on relationship (ROR): The value of relationship marketing and CRM in a B2B context. Journal of Business \& Industrial Marketing, 19(2), 136-148.

Harker, M. J. (1999). Relationship marketing defined? An examination of current relationship marketing definitions. Marketing Intelligence and Planning, 17(1), 13-20.

Hunt, S. D., Arnett, D. B., \& Madhavaram, S. (2006). The explanatory foundations of relationship marketing theory. The Journal of Business \& Industrial Marketing, 21(2), 72-87.

Jain, D., \& Singh, S. (2002). Customer life-time value research in marketing: A review and future directions. Journal of Interactive Marketing, 16(2), 34-46.

Klein, H. K., \& Myers, M. D. (1999). A set of principles for conducting and evaluating interpretive field studies in information systems. MIS Quarterly, 23(1), 67-94.

Kotorov, R. P. (2002). Ubiquitous organization: Organizational redesign for e-CRM. Business Process Management Journal, 8(3), 218-232.

Lee-Kelley, E., Gilbert, D., \& Mannicom, R. (2003). How e-CRM can enhance customer loyalty. Marketing Intelligence \& Planning, 21(4), 239-248.

Leverin, A., \& Liljander, V. (2006). Does relationship marketing improve customer relationship satisfaction and loyalty? The International Journal of Bank Marketing, 24(4), 232-25.

Light, B. (2003). CRM packaged software: A study of organisational experiences. Business Process Management, 9(5), 603-616. 
Kincaid, J. W. (2003). Customer relationship management: Getting it right! Upper Saddle River, NJ: Prentice-Hall.

Massey, A. P., Montoya-Weiss, M. M., \& Holcom, K. (2001). Re-engineering the customer relationship: Leveraging knowledge assets at IBM. Decision Support Systems, 32(2), 155-170.

Morris, M., Brunyee, J., \& Page, M. (1998). Relationship marketing in practice. Industrial Marketing Management, 27, 359-371.

O'Malley, L., \& Prothero, A. (2004). Beyond the frills of relationship marketing. Journal of Business Research, 57, 1286-1294.

O'Toole, T. (2003). E-relationships - Emergence and the small firm. Marketing Intelligence \& Planning, 21(2), 115-122.

Payne, A. F. T., (2000a). "Customer Retention", in Cranfield School of Management (Eds),Marketing Management: A Relationship Marketing Perspective, Palgrave Macmillan, Basingstoke, pp.110122.

—. Payne, A.F.T. (2000b), "Relationship marketing: managing multiple markets", in Cranfield School of Management (Eds),Marketing Management: A Relationship Marketing Perspective, Palgrave Macmillan, Basingstoke, pp.16-30.

Payne, A.F.T., \& Frow, P. (2005). A strategic framework for customer relationship marketing. Journal of Marketing, 69(4), 161-176.

- (2004). The role of multichannel integration in customer relationship marketing. Industrial Marketing Management, 33, 527-538.

Peppard, J. (2000). Customer relationship management (CRM) in financial services. European Management Journal, 18(3), 312-327.

Rayson, P. (2003). Wmatrix: A statistical method and software tool for linguistic analysis through corpus comparison. Unpublished Ph.D. thesis: Lancaster University.

Reichheld, F. F. (2001). The loyalty effect: The hidden force behind growth, profits, and lasting value. Boston: Harvard Business School Press.

Rheault, D., \& Sheridan, S. (2002). Reconstruct your business around customers. Journal of Business Strategy, 23(2), 38-42.

Rigby, D. K., Reichfield, F. F., \& Scheffer, P. (2002). Avoiding the four perils of CRM. Harvard Business Review, 80(2), 101-109.

Ryals, L., \& Knox, S. (2001). Cross-functional issues in the implementation of relationship marketing through customer relationship management. European Management Journal, 19(5), 534-542.

Srivastava, R., Shervani, T. A., \& Fahey, L. (1999). Marketing, business processes and shareholder value: An organisationally embedded view of marketing activities and the discipline of marketing. Journal of Marketing, 63, 168-179.

Trembly, A. (2002). Why CRM has failed in insurance. National Underwriter, 106(26), 25.

Walsham, G. (1993). Interpreting information systems in organizations, Wiley, Chichester.

Walsham, G. (1995). Interpretive case studies in IS research: Nature and method. European Journal of Information Systems, 4(2), 74-81.

Yin, R. (2003). Case study research: Design and methods. Beverley Hills, CA: Sage Publications.

$\mathrm{Yu}$, L. (2001). Successful customer relationship management. MIT Sloan Management Review, 42(4),18-19.

Zablah, A. R., Bellenger, D. N., \& Johnson, W. J. (2004). An evaluation of divergent perspectives on customer relationship management: towards a common understanding on an emerging phenomenon. Industrial Marketing Management, 33, 475-489.

Zuboff, S. (1988). Dilemmas of transformation in the age of the smart machine. New York: Basic Books. 


\section{About the Authors}

Professor Neil F. Doherty (N.F.Doherty@lboro.ac.uk) is Professor of Information Management at Loughborough University Business School, UK. Prior to joining the Business School he spent many years as a programmer and systems analyst, working on a variety of IT projects. His research interests include the treatment of organisational issues in systems development and the impact of strategic IS planning.

Dr Nigel Lockett is Senior Lecturer in Entrepreneurship and Innovation at Brunel Business School, Brunel University, UK and Visiting Research Fellow at Lancaster University Management School, UK. He holds a PhD in Management Science and his research interests include knowledge and technology transfer, e-business and SMEs and systems thinking. 
Table 1: Company characteristics and analysis

\begin{tabular}{|c|c|c|c|c|c|c|c|c|c|}
\hline & $\begin{array}{l}\text { Market } \\
\text { Activity }\end{array}$ & $\begin{array}{l}\text { Company } \\
\text { Age (yrs) }\end{array}$ & Employ & $\begin{array}{l}\text { Turnover } \\
\text { Current }\end{array}$ & $\begin{array}{l}\text { Growth } \\
\text { rate* }^{*}\end{array}$ & $\begin{array}{l}\text { E-C } \\
\text { current }\end{array}$ & $\begin{array}{l}\text { E-C } \\
+1 \text { year }\end{array}$ & B2B & $\mathrm{B} 2 \mathrm{C}$ \\
\hline 1 & $\begin{array}{l}\text { Sport cycles and accessories } \\
\text { Distributing and manufacturing }\end{array}$ & 5 & 13 & 2.0 & $30 \%$ & $\mathrm{n} / \mathrm{a}$ & + & $\mathrm{Y}$ & $\mathrm{N}$ \\
\hline 2 & $\begin{array}{l}\text { Power tools, machinery and } \\
\text { accessories } \\
\text { Distributing }\end{array}$ & 30 & 190 & 24.0 & $25 \%$ & $18 \%$ & $30 \%$ & $\mathrm{Y}$ & Y \\
\hline & Specialist footwear & & & & & & & & \\
\hline 3 & $\begin{array}{l}\text { Designing, distributing and } \\
\text { manufacturing }\end{array}$ & 15 & 82 & 8.0 & $25 \%$ & $12 \%$ & $20 \%$ & $\mathrm{Y}$ & $\mathrm{Y}$ \\
\hline 4 & $\begin{array}{l}\text { Youth clothing } \\
\text { Designing, distributing }\end{array}$ & 6 & 57 & 9.5 & $65 \%$ & $50 \%$ & + & $\mathrm{N}$ & $\mathrm{Y}$ \\
\hline 5 & $\begin{array}{l}\text { Specialist clothing } \\
\text { Designing, distributing }\end{array}$ & 21 & 15 & 1.8 & $15 \%$ & $11 \%$ & + & $\mathrm{N}$ & $\mathrm{Y}$ \\
\hline 6 & $\begin{array}{l}\text { Nutritional and beauty products } \\
\text { Designing and distributing }\end{array}$ & 9 & 170 & Not given & $20 \%$ & $15 \%$ & + & $\mathrm{N}$ & $\mathrm{Y}$ \\
\hline 7 & $\begin{array}{l}\text { Household furnishings } \\
\text { Distributing }\end{array}$ & 2 & $\begin{array}{l}\text { Not } \\
\text { given }\end{array}$ & 0.5 & $\mathrm{n} / \mathrm{a}$ & $20 \%$ & $30 \%$ & $\mathrm{~N}$ & $\mathrm{Y}$ \\
\hline 8 & $\begin{array}{l}\text { Specialist electronics } \\
\text { Designing, distributing and } \\
\text { manufacturing }\end{array}$ & 19 & $\begin{array}{l}\text { Not } \\
\text { given }\end{array}$ & 1.2 & $-20 \%$ & $42 \%$ & + & $\mathrm{N}$ & $\mathrm{Y}$ \\
\hline 9 & $\begin{array}{l}\text { Specialist clothing } \\
\text { Designing and distributing }\end{array}$ & 5 & 13 & 2.0 & $40 \%$ & $46 \%$ & $65 \%$ & $\mathrm{~N}$ & $\mathrm{Y}$ \\
\hline & Average & 12 & 77 & 6.1 & $31 \%$ & $27 \%$ & & & \\
\hline
\end{tabular}




\section{Table 2: Summary and Comparison of Data Analysis Approaches}

Transcribed textual codification: The 'QSR NVivo 2' package is a piece of qualitative data analysis software which has been designed to support the researcher as they attempt to make sense of large sets of qualitative data. More specifically it provides a range of tools for handling rich data records for browsing and enriching text coding it visually and for grouping the data records by many categories. Moreover, the latest version of the software also provides sophisticated modelling options to facilitate the development of theory. For our comparative study the source data came in the form of verbatim transcripts from interviews which were copied into NVivo as Rich Text Files. These transcripts were then used as the key document upon which all the coding and annotation was subsequently applied.

Audio file codification: HyperResearch is a qualitative data analysis software package enabling the coding of multimedia data sources and audio files in particular. Consequently, all the interviews were listened to by the researcher before attempting codify them. This enabled a 'sense' of the whole study to be obtained. Each interview was then codified using HyperResearch. A total of 100 codes where set up and used. These codes emerged as each interview was codified. Interviews were grouped by company to enable the researcher to get a sense of each company in term. Appropriate voice extracts where attributed to each relevant code. This process was repeated again so that any additional codes added during the coding could be applied to previous interviews. An initial HyperResearch report sorted by code was produced and the voice extracts listened to in sequence. This allowed the researcher to determine whether any extracts were inappropriately matched and to get a 'feel' for the importance of the codes in terms of number and the significance of the statement used.

Computer-mediated corpus analysis: In stark contrast to the previous approaches the transcripts were analysed collectively rather than individually. Consequently the individual interview transcripts were concatenated together in plain text form and then submitted for analysis using the Wmatrix software tool (Rayson, 2003). Wmatrix automatically tokenised and then classified every word in the running text into its part-of-speech (POS) and semantic field categories (domains). Frequency profiles of word POS and semantic fields were prepared automatically and key words and key domains emerged by a comparison of the frequency profiles against standard profiles from representative corpora of spoken English in this case almost a million words from the BNC spoken sampler corpus. The log-likelihood statistic was used to indicate significant deviations from the expected frequencies.

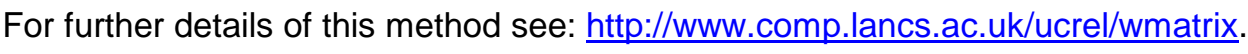



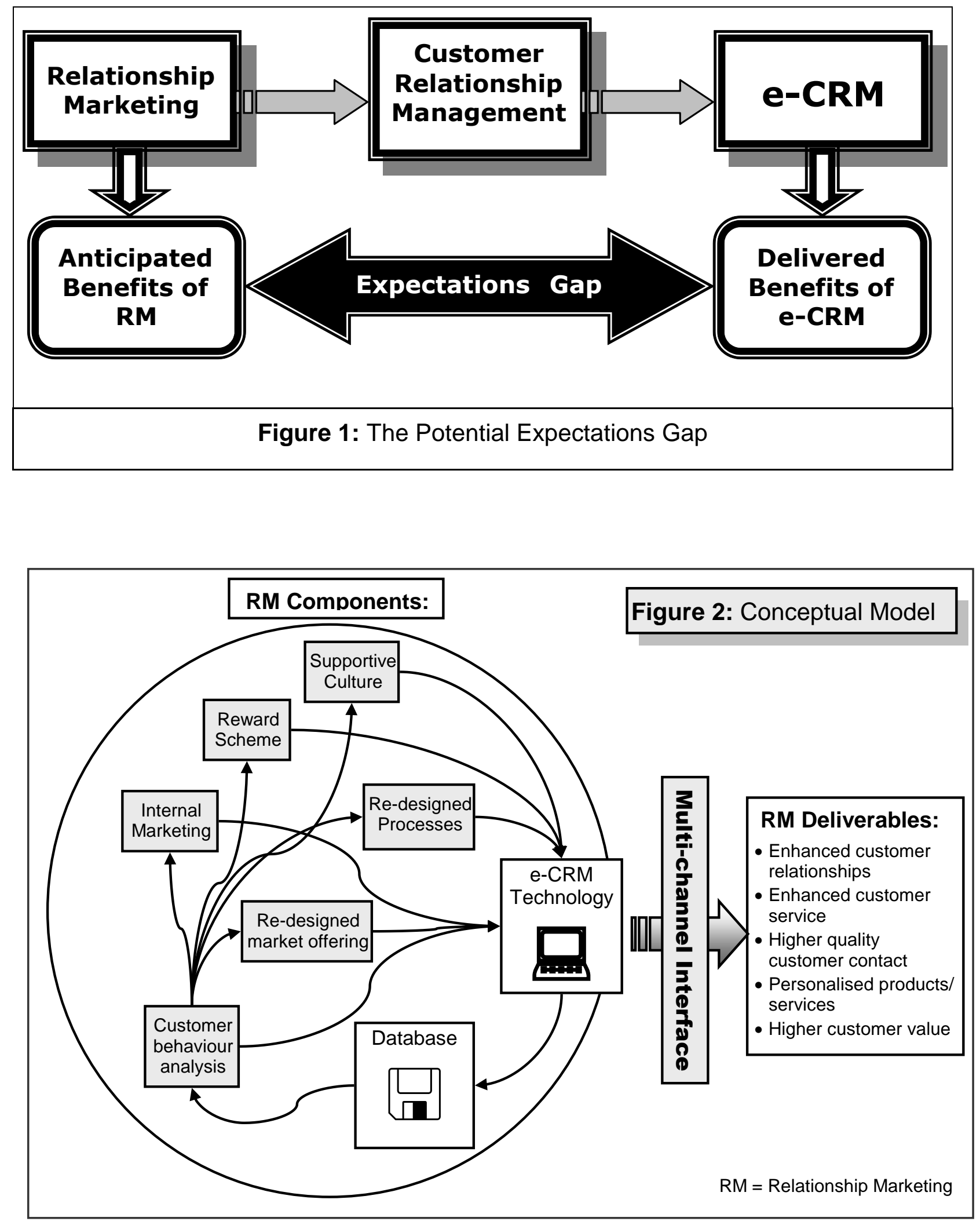


\section{Appendix I - Template for semi-structured interviews}

- Interview characteristics: Name; position; length of service; qualifications; professional experience; roles and responsibilities

- Company characteristics: Name; age; status; ownership structure; organisational structure; turnover; profitable; employees

- Market profile: Description of product and services; markets; channels

- Organisation and management of sales order processing

- Relationship building: Use of IT to acquire, retain and enhance customers

- Information Technology (IT) profile: Description of information systems (IS) used generally and in sales order processing in particular, linkages between IS and sales channels, service providers used; importance of IS; IS strategy, use of IT for relationship building.

- Internet profile: Connectivity; security software / services; description of web site; ecommerce functionality; usage (value, volume, hits and other matrix) from launch (by year); forecast and importance.

- Drivers for e-CRM adoption: Improved process control; greater automation and standardisation of the sales process; improved customer relationships and retention.

- Effectiveness and impacts of e-CRM: Increased efficiency of order processing; improved effectiveness of management information; enhanced customer relationships; level of organisational change. 